\title{
ВИДЫ И ТИПОЛОГИЯ ЭКОНОМИЧЕСКИХ СЕТЕЙ СФЕРЫ УСЛУГ
}

\author{
(C) 2019 Габдрахманов Олег Фаритович \\ кандидат экономических наук, доцент кафедры экономики и финансового права \\ Институт деловой карьеры, Россия, Орехово-Зуево \\ E-mail: Gabdrahmanov@list.ru
}

\begin{abstract}
Рассмотрены характеристики сети юридических лиц, сети предпринимательских структур, сети кредитно-финансового обслуживания, торговые сети, сети франчайзинга, сети Интернет-торговли, сетевой маркетинг (МЛМ-бизнес). Сущность неформальных экономических сетей исследована в тесной увязке с теоретико-методологическими подходами к более общему понятию неформальной экономики, которая за последние годы получила широкую востребованность в научных исследованиях. Результаты данного исследования могут быть полезны специалистам в области менеджмента и экономики, занимающихся проблемами повышения эффективности в современных условиях при изучении теоретических и практических вопросов управления.
\end{abstract}

Ключевые слова: сеть, сфера услуг, классификация, организация, сетевая экономика, модель.

Рассмотреть особенности формирования и функционирования экономических сетей в России весьма затруднительно по причине большого их количества и разнообразия видов, латентности процесса формирования, а также отсутствия принятой системы типологизации. Поэтому, далее рассмотрены основные характеристики наиболее представительных и крупных экономических сетей, оказывающих существенное влияние на сферу услуг РФ: экономические сети домохозяйств, экономические сети на принципах реципрокности, сети юридических лиц, сети предпринимательских структур, сети кредитно-финансового обслуживания, торговые сети, сети франчайзинга, сети Интернет-торговли, сетевой маркетинг (МЛМ-бизнес).

Сетевые формы организации, как условие перехода к современной более сложной и высоко конкурентной экономике представлены в трудах зарубежных ученых М.Грановеттера, М. Кастельса, И. Масуды и других. Значительная группа ученых (C. Grabner, T. Heinrich, M. Kudic, M.O. Jackson, B. Rogers, Y.Zenou и др.) изучали теорию сетей в перспективе ее связи с вопросами социально-экономического развития [1;2].

Отечественные ученые (Б.Ерзнкян, В.Агафонов и др.), используя комплексный междисциплинарный подход, уточнили понятийно-терминологический инструментарий, раскрыли особенности формирования и функционирования сетей, привели их классификацию, разработали модели сетевого бизнеса [3].

Вместе с тем, требуют своего продолжения исследования экономических сетей, определения их роли в сфере услуг, организации, виды, способы создания и т.п., что во многом обусловлено необходимостью модернизации экономики (отражено в работах Н. Акиндиновой, Я. Кузьминова, Е. Ясина и др.) [4].

Экономические сети юридических лиц. Юридические лица создаются как коммерческие и некоммерческие организации, в составе которых, согласно Гражданскому кодексу возможны унитарные и корпоративные формы, но не предусмотрены сетевые сообщества [5].

Число зарегистрированных юридических лиц в России по состоянию на 2017 г. составляет более 5 млн., дающих рабочие места, выплачивающих соответствующие налоги и создающих блага в виде продукции и услуг (рис. 1).

В целом динамика числа предприятий и организаций в РФ имеет явно возрастающий тренд прямой, описываемый закономерностью:

$$
\begin{aligned}
& y=33,25 x+4740,8 \\
& R^{2}=0,7034
\end{aligned}
$$

Наибольший прирост числа предприятий и организаций отмечен в 2015 г., составив 3,2\% по отношению к 2014 г.

В России преобладают предприятия и организации с низкой численностью работников.

Фактическая средняя численность персонала свидетельствует о низком потенциале предприятий и их возможности осуществлять высокотехнологические разработки и выпускать кон- 


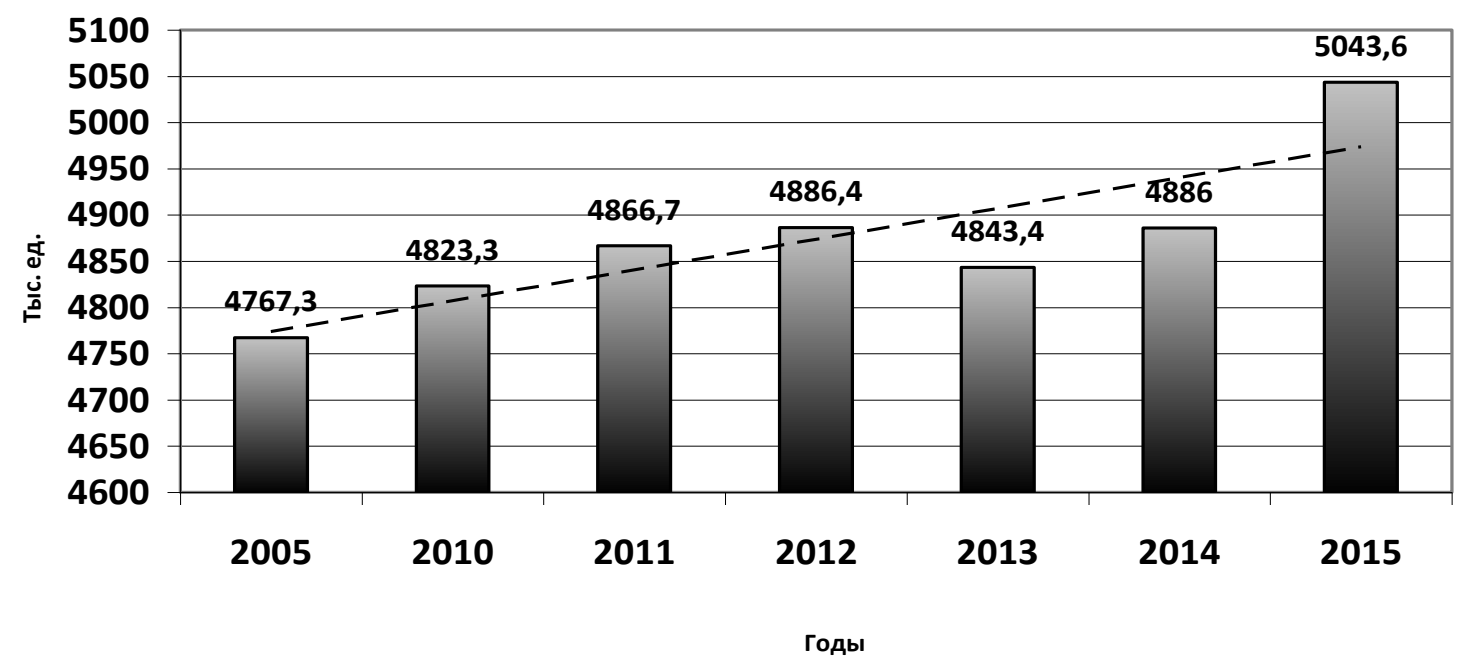

Puc. 1 Динамика числа предприятий и организаций в РФ [6]

курентоспособную инновационную продукцию (услуги). К тому же эта величина продолжает снижаться, составив в 2015 г. 0,97 к величине 2005 г.

Экономические сети предпринимательских структур представляют собой особую децентрализованную форму организационной интеграции и взаимодействия субъектов предпринимательства на основе учета интересов, стремящихся $\mathrm{K}$ долговременному сотрудничеству, расширению рыночного пространства, получению доступа к ресурсам для реализации наилучших совместных возможностей и получения конкурентных преимуществ по сравнению с другими субъектами, не входящими в данное сообщество. Узлами такой сети являются субъекты предпринимательства: юридические и физические лица, зарегистрированные и незарегистрированные, крупные, средние и малые, территориальные органы управления, информация и коммуникации.

Экономические сети предпринимательских структур предполагают в целом снижение влияния внутриорганизационных сил формализованного типа и создание отношений межфирменного сотрудничества в интересах устойчивого развития всей предпринимательской совокупности. Малые и средние предприятия в субъектах России создают сети преимущественно на основе краткосрочных договоров, что придает им нестабильный характер. Сети корпоративной предпринимательской структуры более стабильны, что обусловлено принципами их создания:

- формирование общей философии сотруд- ничества, основанной на взаимной поддержке, ответственности, выгоде, доверии и открытости;

- переход на организацию межфирменного взаимодействия с непостоянной дискретной основы на долгосрочное партнерство;

- снижение роли формализованных взаимоотношений на отношения взаимных обязательств и неформальных соглашений;

- выполнение стратегических программ развития сети. Привлечение участников к управлению;

- развитие и углубление кооперации и разделения труда между участниками;

- обеспечение концентрации ресурсов и активизации всех участников в силу возникающей необходимости на приоритетных направленияX;

- создание условий для развития участников сети и полной реализации их потенциалов.

Общая схема экономической сети корпоративной предпринимательской структуры представлена на рисунке 2 .

Сеть формируется в результате: создания корпораций, которые концентрируют основную часть предприятий региона во взаимовыгодных структурах; заполнения межкорпоративного предпринимательского пространства малыми и средними фирмами.

При этом обеспечивается многоканальное сотрудничество: малого предпринимательства между собой и с корпорациями; часть предприятий региона функционирует самостоятельно, но в различной степени взаимодействует с сетевой структурой, дополняя и развивая ее. 


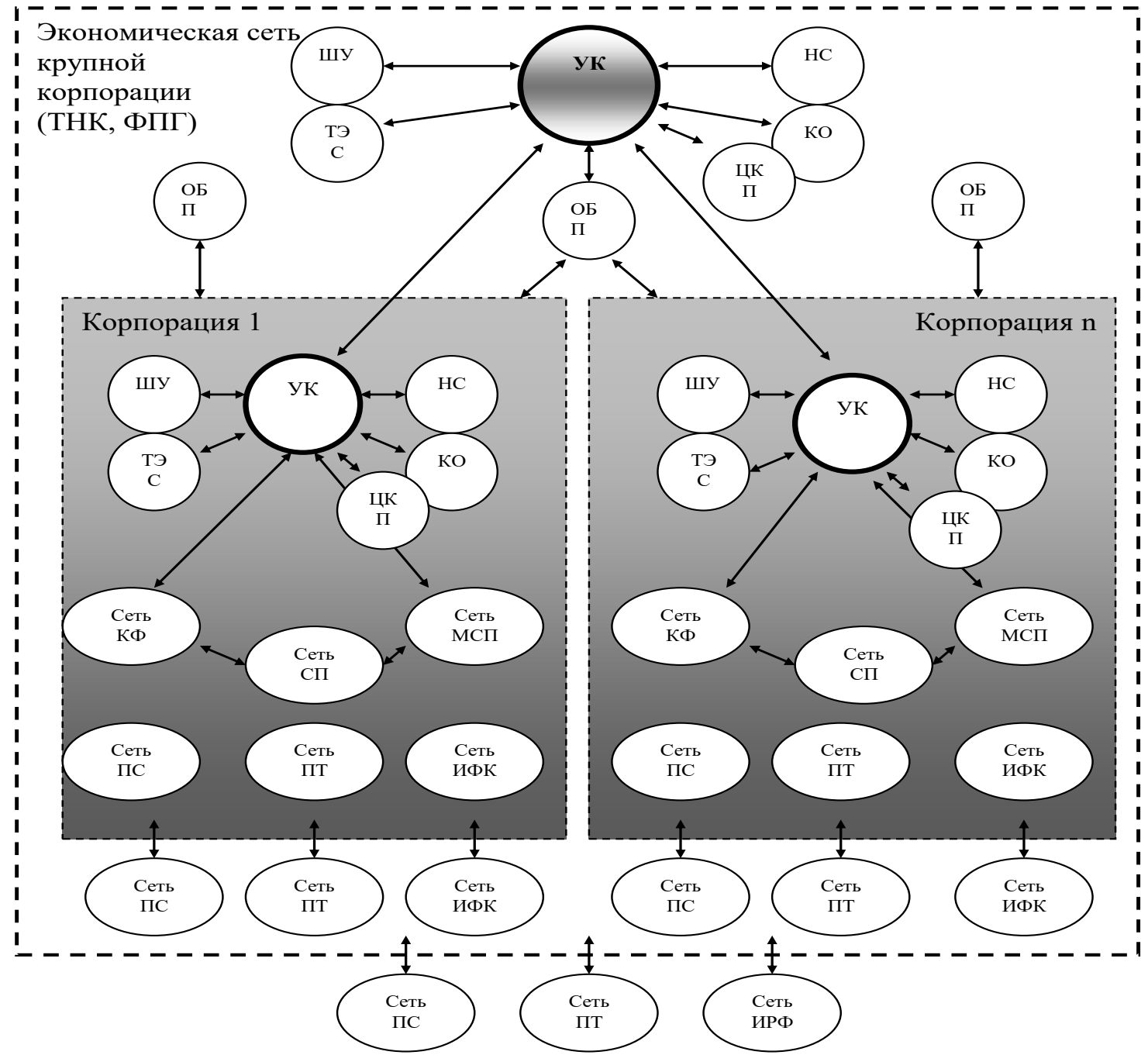

Условные обозначения: УК - управляющая компания; ШУ - штабы управления; НС наблюдательный совет; ТЭС-технико-экономический совет; КО-консалтинговые организации; ЦКП-центры коллективного пользования; ОБП- общекорпоративные подразделения; КФ- крупные фирмы профильной деятельности; МСП - малые и средние предприятия профильной деятельности; СП-смежные предприятия; ПС - компании поставщики; ПТ - потребители; ИФ - объекты инфраструктуры корпорации; ИРФ- объекты рыночной инфраструктуры региона.

Puc. 2 Общая схема экономической сети корпоративной предпринимательской структуры

Экономические сети кредитно-финансового обслуживания включают совокупности организаций, осуществляющих финансовое, кредитно-банковское, инвестиционное обслуживание хозяйствующих субъектов и населения (сети банков, микрофинансовых фондов и фирм, венчурных организаций и т.п.), а также сопутствующих и дополняющих их структур (сети страхования, сети гарантийных организаций, сети финансового консалтинга и т.п.). До конца 80-х гг. XX в. в России была широко распростра- нена официальная сеть государственных сберкасс, осуществляющая прием вкладов населения. В неформальном секторе функционировала сеть материальной взаимопомощи, создаваемая работниками предприятий. В 90-е гг. XX в. стали создаваться экономические сети в виде широко известных финансовых пирамид («МММ», «Властелина», «Русский дом Селенга», «Казачья казна», «Хопер-инвест» и др.). Посредством создания своих филиалов в регионах и крупных городах страны они охватывали огромное чис- 
ло вкладчиков, привлекая и аккумулируя их финансовые средства с обещанием последующих выплат под высокие проценты. Принцип действия таких пирамид - привлечение вкладов все новых желающих обогатиться для выплаты из их средств предыдущим участникам (рис. 3).

Возможности Интернет-технологий предоставляют новые возможности функционированию неформальных экономических сетей финансового обслуживания за счет: расширения географии охвата участников, сокращения материальных затрат на деятельность и рекламу, сокрытия регистрации сайтов, усложнения отслеживания движение вкладов по электронным платежным системам и т.п.

Торговые сети. Российский рынок торговых сетей (сетевого FMCG-ритейла) несмотря на кризисный период активно развивается. Крупнейшие торговые компании активно наращивают свои сети, используя сложную ситуацию в секторе непродовольственной розницы. Для этого они увеличивают объемы инвестиций в развитие региональных представителей или в освоение новых рынков, повышают доли своего участия в капитале за счет поглощения небольших сетей в субъектах России. Такая стратегия приводит к повышению степени концентрации крупных сетевых компаний. В настоящее время почти $23 \%$ российского продовольственного рынка находятся под контролем семи крупнейших компаний, которые открыли дополнительно 2,5 тыс. магазинов [7].
До 2014 года рост ВВП РФ во многом поддерживался в секторе розничной торговле и сфере услуг достаточным уровнем потребительского спроса со стороны населения. После 2014 года эти сегменты в значительной мере потеряли позиции драйвера экономического роста, демонстрируя затухание деловой активности. Нестабильность на геополитическом уровне и негативные последствия санкций вынудили население сократить покупки многих товаров и приобретение необязательных услуг. Домохозяйства реагируют на кризисные проявления стандартным образом, сменяя свою модель поведения с потребления на сбережение, на снижение трат и учет фактора цены при выборе товара или услуг. Это приводит к заметному сжатию потребительского спроса и снижению темпов роста объемов как розничной торговли, так и сумм платных услуг населению.

Сохранение кризисной ситуации в экономике может привести к изменению структуры торговых сетей. Основная тенденция проявит себя в виде снижения суммы среднего чека, сокращения доли крупных форматов розницы с одновременным ростом удельного веса дискаунтеров и магазинов шаговой доступности.

Сети франчайзинга. В составе сетевых форм организации экономической деятельности большое распространение в России получил франчайзинг - вид отношений между сторонами на базе коммерческой концессии, при которой франчайзер передает права франчайзи на

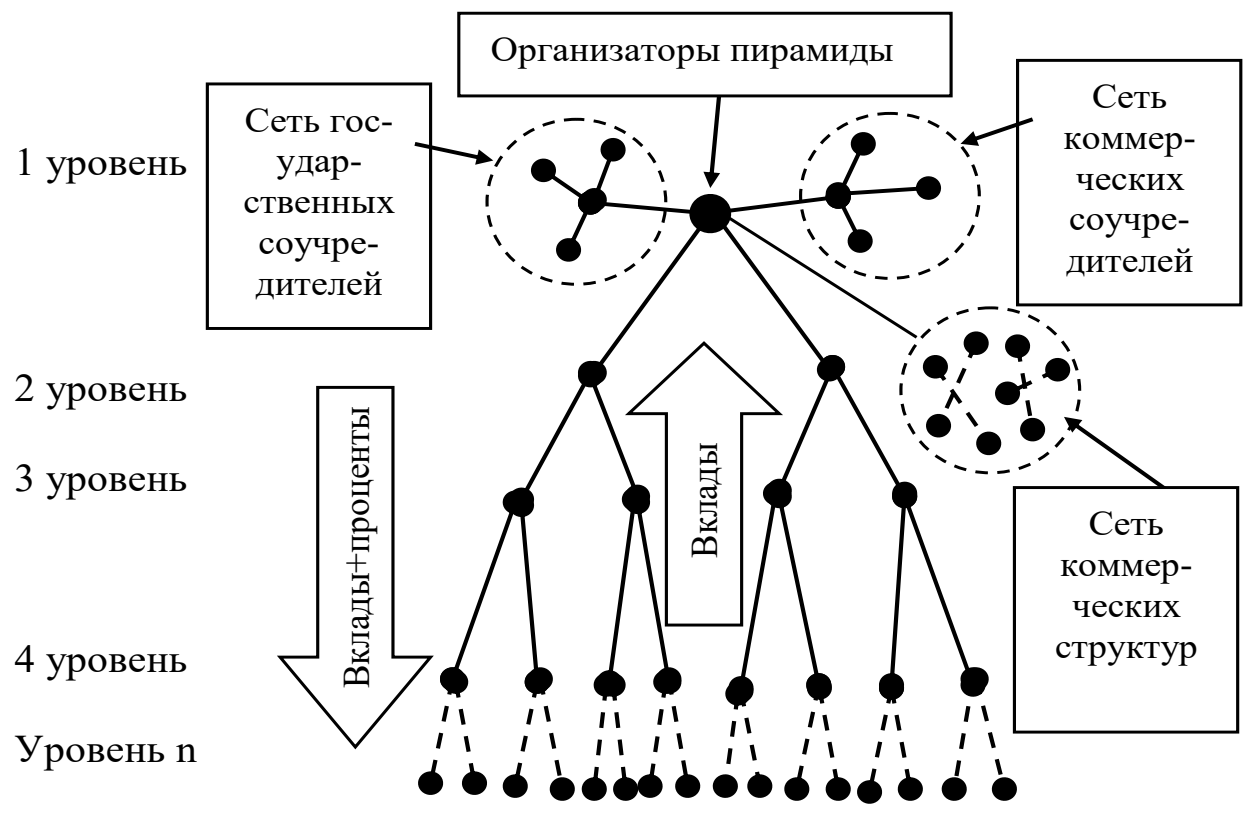

Puc. 3 Схема экономической сети в виде финансовой пирамиды 
осуществление определенного бизнеса на возмездной основе. Используя принципы франчайзинга в России функционируют сеть ресторанов быстрого питания McDonald's, компания 1 C (включает 4,5 тыс. франчайзи), сеть супермаркетов «Пятерочка» (3,8 тыс. точек), «Перекресток (390 магазинов) и т.д.

Сети Интернет-торговли. Оборот 43 тыс. интернет-магазинов России в сумме составляет более 700 млрд. рублей. Если в 2010 году объем деятельности интернет-магазинов составлял 176 млрд. руб., то в 2017 году он возрос до 1250 млрд. руб. (в 7,1 раз). В целом же после 2014 года рост ежегодного оборота рынка Интернет-торговли заметно снизился. При этом инфляционный рост несколько скомпенсировал спад темпов роста числа заказов. Предполагается, что в ближайшее время ежегодный рост Интернет-торговли продолжится с темпом 20-30\%.

В числе драйверов роста сетей Интернет-торговли отмечают: электронику и бытовую технику (почти 150 млрд. рублей); одежду и обувь (около 100 млрд. рублей); компьютерную технику и комплектующие детали (более 70 млрд. рублей); автозапчасти (почти 40 млрд. рублей); мобильные телефоны (более 30 млрд. рублей). В настоящий период в Рунете представлено около 100 тысяч сайтов, которые потенциально обеспечивают заказы. Структура сети интернет-магазинов имеет следующий вид (табл. 1).

Общая тенденция развития сети интернет-магазинов России за последние годы связана с увеличением как числа больших структур, так и их среднего годового оборота. При этом почти 30\% микро-магазинов не получают заказы от клиентов, но и в этой группе магазинов рост суммы среднего чека привел к повышению оборота деятельности.

Сетевой маркетинг (МЛМ-бизнес) основан на концепции реализации товаров крупных международных компаний (Amway, Avon Products, Herbalife Ltd и др.) и предоставления услуг сетью независимых дистрибьюторов (или сбытовых агентов), имеющих право не только сбыта товара, но и привлечения новых партнеров (распространителей).

Общая схема сетевого маркетинга представлена на рис.4.

Сетевой маркетинг по своей организации напоминает пирамиду. Распространителям предоставляется скидка (до 40\%), а за привлечение новых партнеров предлагаются бонусы, например, в виде скидок на следующие партии товара, а также ценные подарки, или бесплатное обучение основам ведения бизнеса. Через сетевой маркетинг распространяется эксклюзивный товар по более низким ценам в сравнении с ценами в «обычном» стационарном магазине. Это связано с тем, что сетевые компании не арендуют торговые площади, снижают налоговую базу, не содержат продавцов, менеджеров, уборщиц и других сотрудников, а значит экономят на аренде, зарплате и т.п.

При этом они создают возможности для заработка своим распространителям (в виде новых рабочих мест). МЛМ-бизнес может иметь форму сетевого партнерства, при котором товары (услуги) участникам предоставляются по выгодным партнерским ценам (рис. 5).

Для того, чтобы получить подобные скидки покупателю следует стать партнером. Сетевой маркетинг нашел широкое применение в мировой экономике. Так, в США в сетевом маркетинге занято 8 млрд. руб., а объем реализации товаров и услуг в год составляет 20 млрд. руб. В мире в сетевом маркетинге занято 30 млрд. руб., а объем реализации товаров и услуг в год составляет более 100 млрд. руб.

\section{Типологии экономических сетей}

Под топологией экономической сети понимается схема соединения ее элементов и передачи информации. Топология отражает конструктивное устройство сети в данный момент времени. Исследование позволило определить, что разные виды экономических сетей сферы услуг имеют топологию традиционных схем в виде дерева, кольца, сети с пассивным и активным центром, открытой и закрытой сети, звезды,

Таблица 1. Структура сети интернет-магазинов по признаку масштаба [8]

\begin{tabular}{|l|c|c|c|c|}
\hline Критерий & $\begin{array}{c}\text { Число интернет- } \\
\text { магазинов }\end{array}$ & $\begin{array}{c}\text { Число заказов в } \\
\text { сутки }\end{array}$ & $\begin{array}{c}\text { Годовой оборот в } \\
\text { год, млн. руб. }\end{array}$ & $\begin{array}{c}\text { Общий оборот, } \\
\text { млн. руб. }\end{array}$ \\
\hline Крупные & 50 & $>1000$ & 4000 & 200000 \\
\hline Средние & 950 & $>50$ & 2000 & 190000 \\
\hline Малые & 6500 & $10-50$ & 20 & 130000 \\
\hline Микро & 35400 & $<10$ & 2,6 & 92040 \\
\hline
\end{tabular}




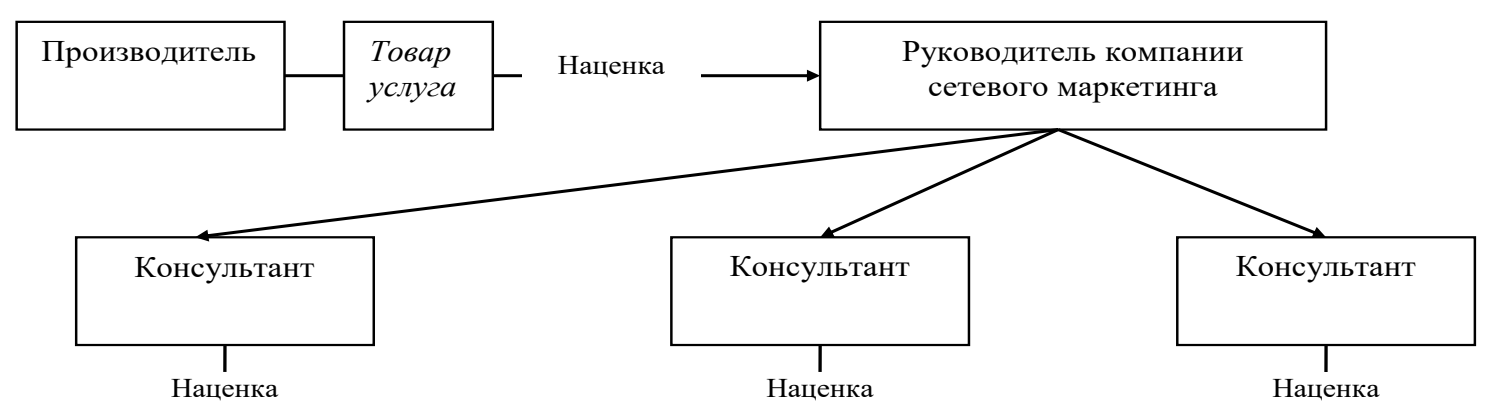

Сеть 1: распррстранители

Сеть 2: распроспранители

Сеть n: распространители Наценка
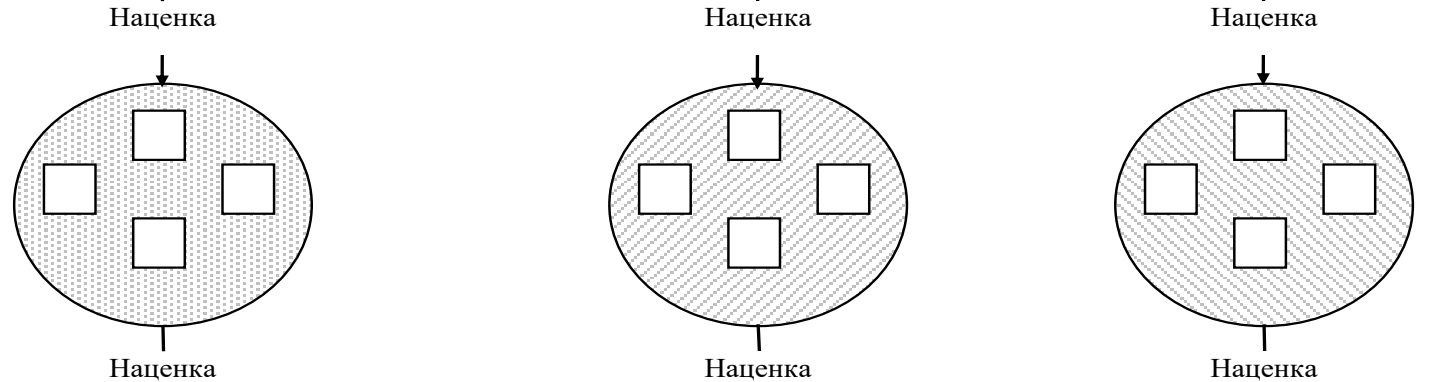

$\downarrow$

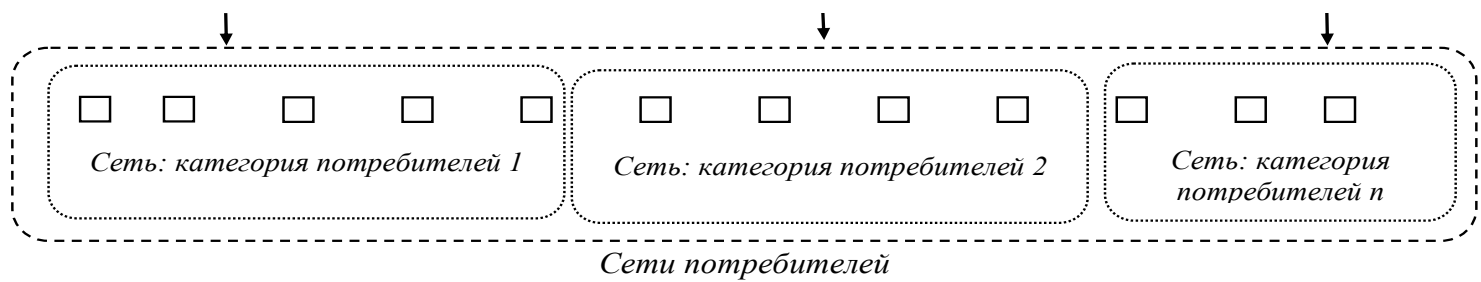

Рис.4 Схема сетевого маркетинга

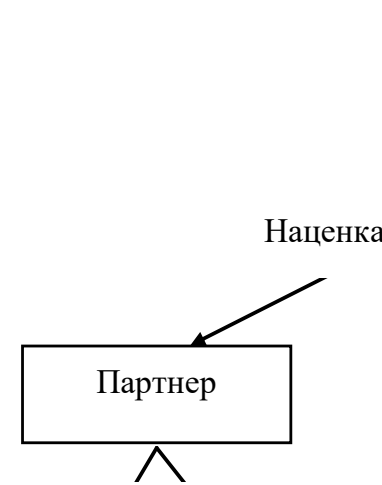

Наценка

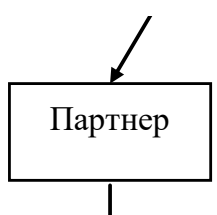

Наценка

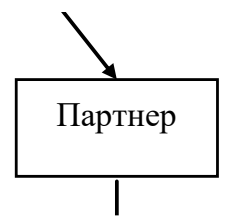

Наценка

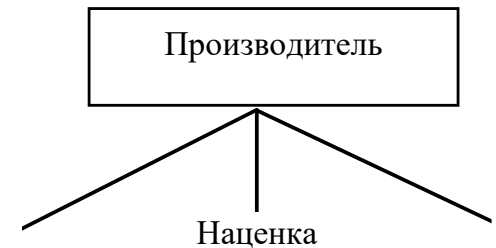

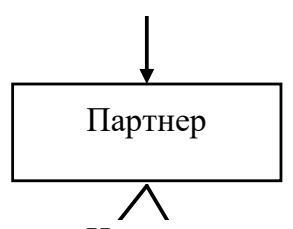

Наценка

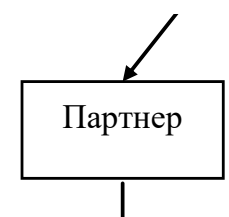

Наценка

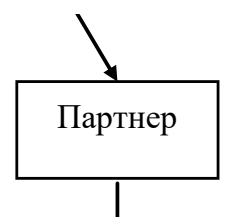

Наценка
Наценка

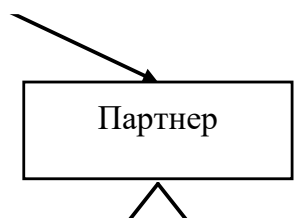

Наценка

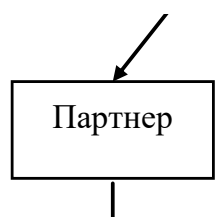

Наценка

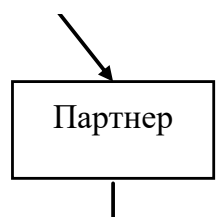

Наценка

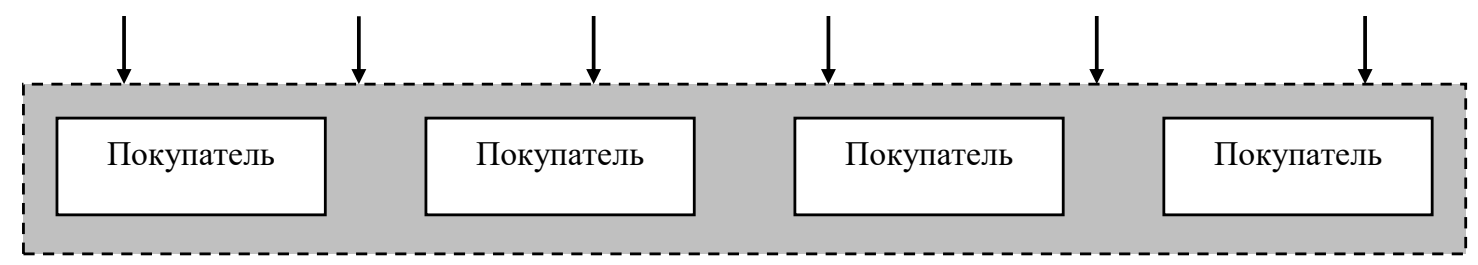




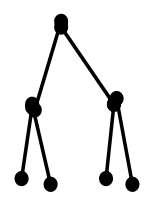

Дерево

Кольцо

Сеть с центром

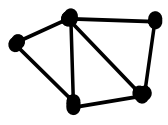

Сеть закрытая
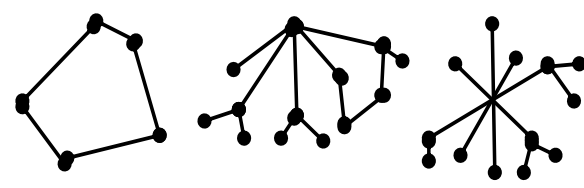

Сеть с пассивным центром

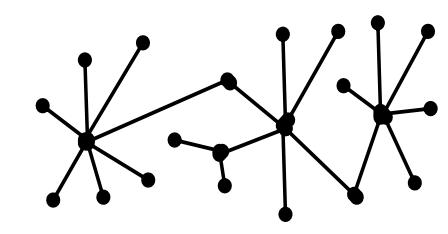

Сеть

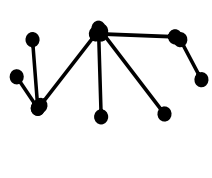

Сеть открытая

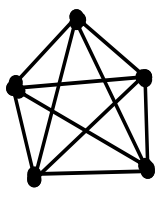

Сеть звезда

интегрированная

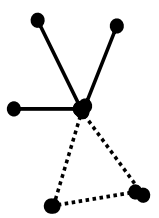

Сеть формальнонеформальная (теневая) «двойного закрытая назначения»

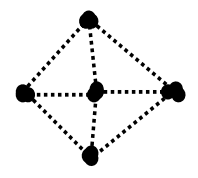

Сеть неформальная закрытая

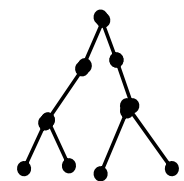

Сеть иерахическая иерархическая формальная неформальная

\footnotetext{
Условные обозначения: О - субъекты сети; - - открытые связи;

•.......• - неформальные субъекты и связи сети
}

Puc. 6 Топология экономических сетей сферы услуг России

полносвязанной сети, интегрированной сети и т.д. (рис. 6).

Кроме приведенных схем существуют и другие топологии экономических сетей, общий вид которых не имеют четко определенных конфигураций.

На характер топологии оказывает влияние ряд следующих факторов: размер и сложность структуры сети; уровень централизации сети и характер принимаемых в ней управленческих решений; необходимость дублирования элементов сети с целью повышения надежности их функционирования; наличие ресурсов и стоимость содержания сети и т.п. Следует также учитывать, что конструкция сетей является динамичной и их топология изменяется в зависимости от многих обстоятельств. Так, например, на характеристики экономической сети оказывают значительное влияние стейкхолдеры - заинтересованные субъекты в ее существовании, как внутренние (собственники, менеджеры, со- трудники, участники и др.), так и внешние (потенциальные инвесторы, акционеры, заказчики и клиенты, поставщики, партнеры и конкуренты, органы государственной власти и местного самоуправления, предприятия и т.п.).

В ходе исследования проверялись и были опровергнуты два популярных мнения о том, что:

- неформальные сети состоят из небольших групп людей, потерявших работу, не востребованных рынком, или недостаточно занятых по месту основной работы;

- скрытая неформальная экономическая деятельность является экономически малоэффективной и в основном направлена на обеспечение минимально возможных доходов беднейших групп населения.

Обнаружено наличие экономических сетей «двойного назначения», созданных в виде сочетания формальных и неформальных сетевых структур для продвижения ресурсов из откры- 
тых секторов экономики в теневые, скрытые для наблюдения. Формальная часть подобной экономической сети, как правило, обладает открытой структурой для внешнего наблюдателя и доступную для вступления желающих в ее состав, а скрытая неформальная ее часть имеет топологию сети закрытого вида. Это означает, что многие формальные экономические сети (крупные, средние и малые) создают свой скрытый (теневой, нерегистрируемый, неучтенный и т.п.) сектор, в котором они осуществляют свою деятельность наряду с явно неформальными структурами. К таким видам деятельности экономических сетей «двойного назначения» можно отнести грузовые и пассажирские перевозки, ремонтно-строительные работы, торговую деятельность и т.п.

Также выявлено, что чем больше размер экономической сети, тем более значимую (по объемам) скрытую деятельность она осуществляет. В этой связи основными субъектами на теневом рынке являются крупные коммерческие сети, контролирующие целые направления экономической деятельности.

Одновременно выявлено, что основная часть занятых в неформальных экономических сетях обеспечивает производительный, экономически эффективный характер деятельности, приносящей прибыль для основных ее субъектов. Конечно, подобные сети могут иметь ограниченные возможности по применению современных наукоемких технологий, однако, использование других не менее выгодных факторов, позволяет им с высоким уровнем рентабельности покрывать все свои понесенные затраты.

Следует также отметить, что в обществе недостаточно понимается характер деятельности неформальных сетей сферы услуг, что связано с внешне низкими доходами большинства занятых в них работников (в сравнении со средними величинами оплаты труда в формальной экономике), с неквалифицированным трудом, с нарушениями прав работников и другими недостатками. Считается, что все проблемы детерминировано определяются самой негативной сущностью неформального сектора экономики, априори носящего антигосударственный (или антиобщественный) характер и из которого не могут «выбраться» те, кто не способен по причине своего физического состояния, профессиональной подготовки, психических и других качеств эффективно трудиться на официальных рабочих местах.

Подобная точка зрения имеет широкое распространение среди служащих государственных органов и сотрудников служб занятости, анализирующих и интерпретирующих ситуацию с безработицей в регионе. Причины образования неформальных экономических сетей и проблемы в них существующие во многом создаются и получают развитие именно в формальной экономике и обусловлены совокупностью факторов, которые требуют регулярного исследования и анализа. Так, например, представляется целесообразным проводить исследование тенденций занятости в регионе одновременно в формальном и неформальном секторах экономики. Ведь если уровни занятости в разных секторах экономики носят разновекторный характер, то это может характеризовать наличие одной ситуации, а наличие тенденций одновекторного характера предполагает совершенно другое развитие событий, что предопределяет соответствующие управленческие решения в этой области.

Кроме того, наличие форм сетевой организации экономической деятельности в конкретном секторе сферы услуг означает специальный способ ведения деловых операций и взаимодействий, характеризующийся:

- более легким и быстрым входом новых участников в совместное дело (или на рынок) при согласии и поддержке стейкхолдеров;

- наличием опоры на совместные ресурсы (материальные, человеческие, финансовые и др.), которые уже накоплены и активизированы в рамках действующей сети;

- коллективной собственностью участников сети, их совместной ответственностью за сохранение и приумножение капиталов;

- масштабностью работ (в сравнении с индивидуальной занятостью), что позволяет более полно и гибко реализовать человеческие возможности;

- возможностью применения более современных и адаптированных к условиям сети технологий и оборудования, что потенциально способно повысить уровень эффективности;

- полным и ускоренным освоением навыков работы, приобретенных не в рамках формальных систем подготовки работников (и поэтому, зачастую, низкоэффективных), а в реально-практических условиях.

Состояние и деятельность экономических сетей (в том числе в неформальном секторе) не 
должна игнорироваться со стороны общества и государства в плане их исследования, поддержки и регулирования. Предполагается необходимым переориентации подходов и стратегий действий от традиционного противостояния на установление благоприятных тесных связей и взаимодействий, которые до настоящего времени не сложились между формальным и неформальным секторами экономики, между сетевыми формами и иерархическими структурами.

Исследование основных типов наблюдаемых экономических сетей в сфере услуг Российской Федерации позволяет сделать выводы, что общей проблемой экономики страны является влияние фактора низкой оплаты труда, которая привела к появлению феномена «работающих бедных», которые не в состоянии обеспечить себя, будучи занятыми на одной работе и вынуждены искать дополнительную подработку на стороне. В этой связи в стране проявляют себя многофакторные условия для расширения форм теневой экономики не только применительно к нерегистрируемой занятости, но и другим ее аспектам (скрытой оплате труда, нарушений режимов труда и отдыха, ухода от социальных обязательств и т.п.). К числу основных причин ухода «официальных» работников в теневой сектор, следует отнести сокращения с официальной работы, скрытую безработицу, нехватку рабочих мест, а также неблагоприятные условия осуществления бизнеса и поддержки функционирования предприятий.

В России наблюдается большое многообразие форм экономических сетей, что является следствием их естественного отбора в результате сочетания огромного числа факторов конкуренции и условий рыночной среды. Можно констатировать, что почти все они могут быть отнесены к неформальным сетям по причине отсутствия в законодательных и нормативно-пра- вовых документах страны понятийно-категориального инструментария, определяющего их терминологию, содержание, способы создания и функционирования, роль в экономике и т.п. Правовое и методическое обеспечение экономических сетей отстает от фактического положения дел в экономике страны, что затрудняет идентификацию форм устройства экономических сетей с учетом разных условий существования и деятельности (территориальных, отраслевых и др.), выбор хозяйствующими субъектами соответствующих комбинаций взаимодействия и критериев оптимальности, не позволяет исследовать рациональность сетевого устройства экономики России и определять его уровень.

Выявлено, что многие формальные экономические сети (крупные, средние и малые) имеют свой скрытый (теневой, нерегистрируемый, неучтенный и т.п.) сектор, в котором они осуществляют свою деятельность наряду с неформальными структурами. При этом обнаружена прямая корреляционная связь между размером экономической сети и объемами ее скрытой деятельности. Основная часть занятых в неформальных экономических сетях обеспечивает производительный, экономически эффективный характер деятельности, приносящей прибыль для основных ее субъектов, что позволяет им покрывать все свои понесенные затраты.

Для решения этих проблем рекомендуется провести переориентацию подходов и стратегий действий от традиционного противостояния на установление благоприятных тесных связей и взаимодействий, которые все еще до настоящего времени не сложились между формальным и неформальным секторами экономики, между сетевыми формами и иерархическими структурами.

\section{Библиографический список}

1. Network theory and social economics - a promising conjunction? Claudius Grabner and Torsten Heinrich and Muhamed Kudic Institute for Institutional and Innovation Economics (IINO), University of Bremen, Bremen, Germany; and, Institute for New Economic Thinking (INET), University of Oxford, Oxford, UK; and, Stifterverband fur die Deutsche Wissenschaft, Wissenschaftsstatistik, Essen, Germany 20 January 2017. URL: https://mpra. ub.uni-muenchen.de/76423.

2. Matthew O. Jackson, Brian Rogers and Yves Zenou. IFN Working Paper No. 1116, 2016. The Economic Consequences of Social Network Structure. Research Institute of Industrial Economics. URL: http://www.ifn.se/wfiles/wp/wp1116. pdf.

3. Ерзнкян Б.А. Сетевая природа кластерной системы и основные направления формирования кластерной стратегии мезоэкономического развития России / Б.А. Ерзнкян, В.А. Агафонов // Экономическая наука современной России. 2011. № 1. С.39-48. 
4. Акиндинова Н. Экономика России: перед долгим переходом / Н. Акиндинова, Я. Кузьминов, Е. Ясин // Вопросы экономики. 2016. № 6. С.3-35.

5. Гражданский кодекс РФ. 30 ноября 1994 г. № 51-ФЗ. URL: http://www.consultant.ru/document/cons_doc_ LAW_5142/

6. Регионы России. Социально-экономические показатели. 2017: Стат. сб. / Росстат. М., 2017. 1402 с.

7. Розничные торговые сети по продаже продуктов питания и сопутствующих товаров (FMCG) в России. Общие характеристики бизнеса, региональный анализ, стратегия развития отрасли. PБК research. 65 c.

8. Аналитический бюллетень InSales: Рынок Интернет-торговли в России. URL: http://www.pvsm.ru/internetmagazin/91035/print. 